\title{
A new species and a key to the species of Corticarina from Guatemala (Coleoptera, Latridiidae)
}

\author{
Jose Carlos Otero', José Manuel Pereira' \\ I University of Santiago de Compostela, Department of Zoology, Genetics and Physical Anthropology, Santiago \\ de Compostela 15782, Spain \\ Corresponding author: José Manuel Pereira (josse33@hotmail.es)
}

Academic editor: Michael Thomas | Received 9 May 2018 | Accepted 11 August 2018 | Published 25 September 2018

http://zoobank.org/92E6A066-7C27-4738-A914-2C213D683E0C

Citation: Otero JC, Pereira JM (2018) A new species and a key to the species of Corticarina from Guatemala (Coleoptera, Latridiidae). ZooKeys 786: 69-73. https://doi.org/10.3897/zookeys.786.26553

\begin{abstract}
A new species of Corticarina Reitter, 1881 (Coleoptera: Latridiidae), Corticarina oscargloriorum sp. n. from Guatemala is described and illustrated. The differential diagnosis is established in relation to a group of other species of the genus.
\end{abstract}

\section{Keywords}

Corticarina oscargloriorum sp. n.; Guatemala; new species; taxonomic key; taxonomy

\section{Introduction}

Latridiidae is a moderately large family with approximately 500 species which is represented in all major biogeographic regions. The genus Corticarina is distributed in the Holarctic, Neotropical, Afrotropic and Oriental regions (Rücker 2009). In Central America, the fauna of Corticariinae is presumably extraordinarily rich, however, little known despite the attention that some authors (Johnson 1978, 1981, 1997; Reike 
2015; Rücker 1981a, 1981b, 1987; Sharp 1902) have paid to some genera of this family (Melanophthalma Motschulsky, Corticarina Reitter, Cortinicara Johnson, etc.). Twenty species of Corticarina are known from Central America. Four of them, considered in this article, are distributed exclusively in Guatemala (Rücker 2009). As a result of that work, we have had the opportunity to study additional material collected in Central America (Zoological Museum, University of Lund, Sweden). Presumably most species considered in this article are endemic to Guatemala. The present paper presents part of the material collected at Sierra Madre Oriental in Guatemala.

\section{Materials and methods}

The terminology and the measurements of the new species follow Otero (1997) and Otero and López (2016). Structures were measured under a Leica M205C- stereomicroscope equipped with an Application Suite analysis system.

Abbreviations:

L length;

WL width/length ratio;

E eccentricity of the eyes (width/half of the length).

The width is measured across the widest part of a line joining the anterior and posterior limit of the eye. Length is the maximum length of the eye. $\mathbf{L}$ is used for length in dorsal view, $\mathbf{W}$ for width, and $\emptyset$ for diameter.

Institutional abbreviations:

USC Universidad de Santiago de Compostela, Spain;

ZML Zoological Museum, University of Lund, Sweden.

\section{Taxonomy}

\section{Gen. Corticarina Reitter, 1881}

Type species. Corticarina truncatella Mannerheim, 1844

Diagnosis. Head generally much narrower than the pronotum. Pronotum rather broad, usually strongly curved at the sides, with or without a circular post median impression; hind angles clearly toothed. Basal segment of the tarsi (especially the hind) strongly produced ventrally so that its apex almost reaches the apex of the second segment; second tarsomere reduced, arising dorsally from the basal segment nearly at the middle. Male: front tibia with a tooth situated at or a little in front of the middle; aedeagus strongly sclerotized, asymmetrical, the ostium ventral and covered with a plate which is usually strongly projecting apically. 


\section{Corticarina oscargloriorum sp. $\mathbf{n}$.}

http://zoobank.org/8A6EE954-93DB-49BB-9E47-B635F64AD1DE

Figures 1-4

Material examined. "Holotype m*. GUATEMALA. Jalapa, Pino Dulce, Mataquescuintla, $14.5256528^{\circ} \mathrm{N}, 90.1453500^{\circ} \mathrm{W}, 28 . X .2016,2.400 \mathrm{~m}$ ”. Holotype placed in Coll. J. C. Otero (USC).

Diagnosis. Morphologically, Corticarina oscargloriorum is very similar to other Corticarina in many external features, but can be distinguished by the configuration of the male genital apparatus and the features in the key below.

Description. Length: $1.1 \mathrm{~mm}$. Body oval, convex and little bright (Figure 1). Yellowish grey-brown; antennae (except for the two first articles) and tibiae dark greybrown; two first articles of antennae and legs yellowish grey-brown. Metathoracic wings fully developed.

Head (Figure 1) slightly transverse (WL $=1.8-1.9)$. Labrum arcuate at anterior margin. Eyes large $(\mathrm{L}=0.073 \mathrm{~mm})$ and little protruding $(\mathrm{E}=0.5-0.6)$; eye facets as large as head punctures. Puncturation very fine $(\varnothing=0.006-0.007 \mathrm{~mm})$ and sparse, barely distinct. Temples indistinct. Antennae (Figure 2) long $(\mathrm{L}=0.398 \mathrm{~mm})$. First antennomere spherical, almost as wide as long; second slightly shorter and half as thin as first; from fourth to seventh almost identical and half as short as second; eighth as wide as long; ninth sub-conical, longer than wide and 1.2 times as long as tenth; tenth 1.1 times longer than wide; eleventh twice as long.

Pronotum (Figure 1) moderately convex and little transverse (WL $=1.2-1.3)$; greatest width at anterior third. Lateral margins regularly rounded and denticulate. Postmedial circular depression present; lateral impressions somewhat distinct. Pubescence whitish, short $(\mathrm{L}=0.019-0.020 \mathrm{~mm})$ and recumbent. Punctation fine $(\varnothing=$ $0.011-0.012 \mathrm{~mm})$ and sparse.

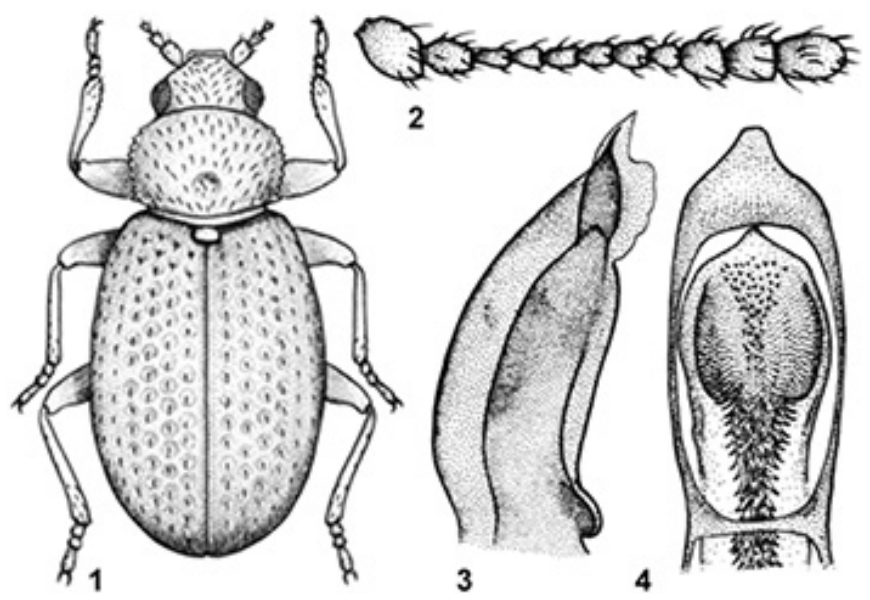

Figures. I-4. Corticarina oscargloriorum sp. n., male, holotype: (I) habitus; (2) antenna; (3-4) aedeagus (lateral and ventral views). 
Elytra 1.5 times as long as wide. Callosity humeralwell-marked and posteriorly prolonged until becoming slightly carenated in the humeral region. Pubescence short $(\mathrm{L}=0.016-0.018 \mathrm{~mm})$ and recumbent. Punctation fine $(\varnothing=0.014 \mathrm{~mm})$ and sparse Six abdominal sternites visible. Male pro-tibiae with a tooth on internal apical third.

Aedeagus (Figs. 3, 4) sub-lanceolate with a small apical protuberance. Internal sac with numerous small spines.

Etymology. This species is dedicated to Óscar Medinilla and Gloria de Dios, Guatemala.

Distribution. Guatemala.

Biology. It has been captured by stirring different types of plant formations.

\section{Key to the Corticarina species from Guatemala}

1 Tenth antennomere distinctly transverse; ninth squared. Spine of male protibiae on the last quarter of the internal margin. Aedeagus (Fig.5). L: 1.4-1.5 mm. Guatemala guatemalica Johnson

- $\quad$ Tenth antennomere as long as wide or longer than wide 2

2 Ninth antennomere conical, wider than long; tenth as long as wide. Light brown; legs yellowish grey-brown; antennae pale on the base however darkening towards the apex. Spine of male pro-tibiae in the middle of the internal margin. Aedeagus (Fig. 7). L: 1.4-1.6 mm. Guatemala..... conjuncta Johnson

- $\quad$ Ninth antennomere markedly longer than wide..................................... 3

3 Pale colour; head and pronotum slightly darker; antennae and legs entirely (except for the antennal club) yellowish grey-brown. Ninth antennomere conical and longer than wide; tenth longer than wide and slightly shorter than ninth. Spines of male pro-tibiae arranged on the middle of the internal margin. Aedeagus (Fig. 6). L: 1.4-1.6 mm. Guatemala

impensa Johnson

- Yellowish grey-brown; antennae (except for the two first articles) and tibiae dark greybrown; two first articles of the antennae and legs yellowish greybrown. Ninth antennomere (Fig. 2) sub-conical, longer than wide; tenth 1.1 times longer than wide and slightly shorter than ninth. Spines of pro-tibiae on apical third. Aedeagus (Figs. 3\& 4). L: $1.1 \mathrm{~mm}$. Guatemala

oscargloriorum sp. $\mathbf{n}$.

\section{Discussion}

Four species for Corticarina have been recorded from the Guatemala to date, and the four species are known to the authors. Morphologically, Corticarina oscargloriorum is very similar to other Corticarina which are remarkably uniform in appearance. Their male genitalia fortunately provide excellent diagnostic characters and are thus essential for identification. 


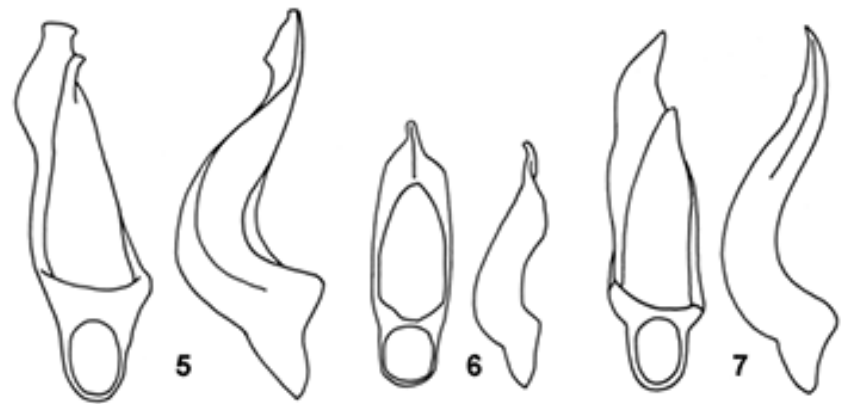

Figures. 5-7. Adeadeagi of species of Corticarina, ventral and lateral views: (5) Corticarina guatemalica; (6) Corticarina impensa; (7) Corticarina conjuncta.

\section{Acknowledgements}

We would like to thank Dr. W. H. Rücker for comments and suggestions, and we appreciate the corrections made by the reviewers.

\section{References}

Johnson C (1978) New species of Corticarina Reitter (Col., Latridiidae). Entomologist's Monthly Magazine 114: 55-62.

Johnson C (1981) New species of Corticarina Reitter (Col., Lathridiidae), part 2. Entomologist's Monthly Magazine 117: 117-123.

Johnson C (1997) Ten new species of Corticarina Reitter (Col.: Latridiidae) from Central and South America. Entomologist's Record 109: 115-124.

Otero JC (1997) Three new species and distributional records of Micrambe C. G. Thomson, 1863 and Cryptophagus Herbst, 1792 (Coleoptera: Cryptophagidae) from Israel and Turkey. Revue Suisse de Zoologie 104(1): 207-216. https://doi.org/10.5962/bhl.part.79997

Otero JC, López MJ (2016) Coleoptera Latridiidae. In: Ramos MA, et al (Eds) Fauna Ibérica, vol. 42. Museo Nacional de Ciencias Naturales, CSIC, Madrid, 288 pp.

Reike H-P (2015) Eine neue Art der Gattung Corticaria aus der sylvicola-Gruppe und eine neue Corticarina (Coleoptera, Latridiidae). Latridiidae and Merophysiinae 18: 1-4.

Rücker HW (1981a) Neue Arten der Gattung Melanophthalma Motschulsky aus Panama (Coleoptera, Lathridiidae). Entomologische Blätter 77: 161-164.

Rücker HW (1981b) Revision der Motschulsky-Typen aus Nord-und Südamerika, Coleoptera: Lathridiidae, Melanophthalma Motschulsky. Entomologische Blätter 77: 161-164.

Rücker HW (1987) Neue Arten der Gattung Melanophthalma Motschulsky aus der neotropischen Region (Coleoptera: Latridiidae). Entomologische Blätter 83 (1): 1-12.

Rücker HW (2009) Checklist Latridiidae and Merophysiinae of the world. Latridiidae: Mitteilungsblatt für Systematik und Taxonomie nder Latridiidae, 9: 1-15.

Sharp D (1902) Lathridiidae in Biologia Centrali Americana. Insecta Coleoptera 2(1): 626-638. 